\title{
Spontaneous spinal subarachnoid haemorrhage: a not so benign disease with devastating results
}

\author{
María Rico, ${ }^{1}$ Elena Reimunde, ${ }^{2}$ Alexandra Figueroa, ${ }^{1}$ Sayoa Eulate-Beramendi ${ }^{3}$
}

${ }^{1}$ Department of Neurology, Hospital de Cabueñes, Oviedo, Asturias, Spain

${ }^{2}$ Department of Radiology, Hospital de Cabueñes, Oviedo, Asturias, Spain

${ }^{3}$ Department of Neurosurgery, Hospital Universitario Central de Asturias, Oviedo, Asturias, Spain

\section{Correspondence to} Dr María Rico, mricos@gmail.com

Accepted 11 January 2016
CrossMark

To cite: Rico $M$, Reimunde E, Figueroa $\mathrm{A}$ et al. BMJ Case Rep Published online: [please include Day Month Year] doi:10.1136/bcr-2015213556

\section{DESCRIPTION}

A 67-year-old male presented with sudden right hemiplegia. One hour before he had complained of mild cervicalgia, but physical examination at the time revealed neither neurological deficits nor stiffness of the neck. He had been admitted to the hospital the day before due to acute biliary pancreatitis, with elevated transaminases but normal blood coagulation testing. He had no history of trauma. Twenty minutes after the onset

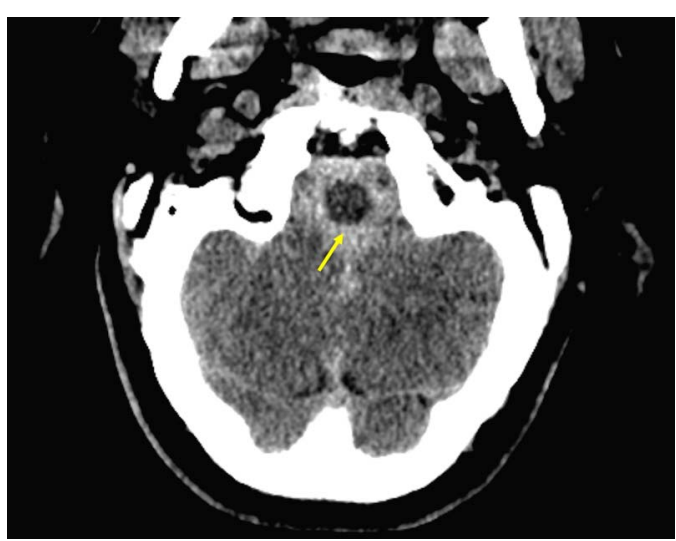

Figure 1 Brain CT scan demonstrating the presence of blood (arrow) in the pontine cistern surrounding the brainstem. plegia on the left leg and moderate paresis on the left arm appeared. The level of consciousness was preserved and the cranial nerves function was normal. No clear sensory level was present.

Brain CT scan demonstrated the presence of blood in the pontine cistern surrounding the brainstem (figure 1). CT of the cervical spine showed a haematoma in the cervical spine that seemed to be located in the subarachnoid space, displacing and compressing the spinal cord forward (figure 2). CT angiography ruled out the presence of aneurisms.

The patient was transferred to the referral hospital and entered surgery $4 \mathrm{~h}$ after the initial pain. Through a C3-C4-C5 bilateral laminectomy it was confirmed the restriction of the haematoma to the subarachnoid space. Manoeuvres of washing and aspiration of the haematoma were performed and the spinous processes were not replaced due to severe spinal cord oedema.

Despite urgent treatment and removal of most of the clot the patient remained with severe paraparesia, plegia on the right arm and mild paresis on the left arm. Two spinal MRI were performed, the first 2 weeks after surgery (figure $3 \mathrm{~A}$ ) and the second one 6 months later (figure 3B). Both failed to detect evidence of spinal tumours or signal voids that could suggest the presence of a vascular malformation. Taking these results into account and the absence of suggestive symptoms a catheter angiography was ruled out.

Figure 2 Cervical spine CT (A) sagittal reconstruction image. The hyperdense effect of the blood in the subarachnoid space can be seen down to the lower levels of the cervical spine (arrow). The blood concentrates mostly in the dorsal side of the subarachnoid space and displaces the spinal cord forward. (B) Axial cut of the spinal cord (open arrow) pushed forward by the haematoma (arrow).

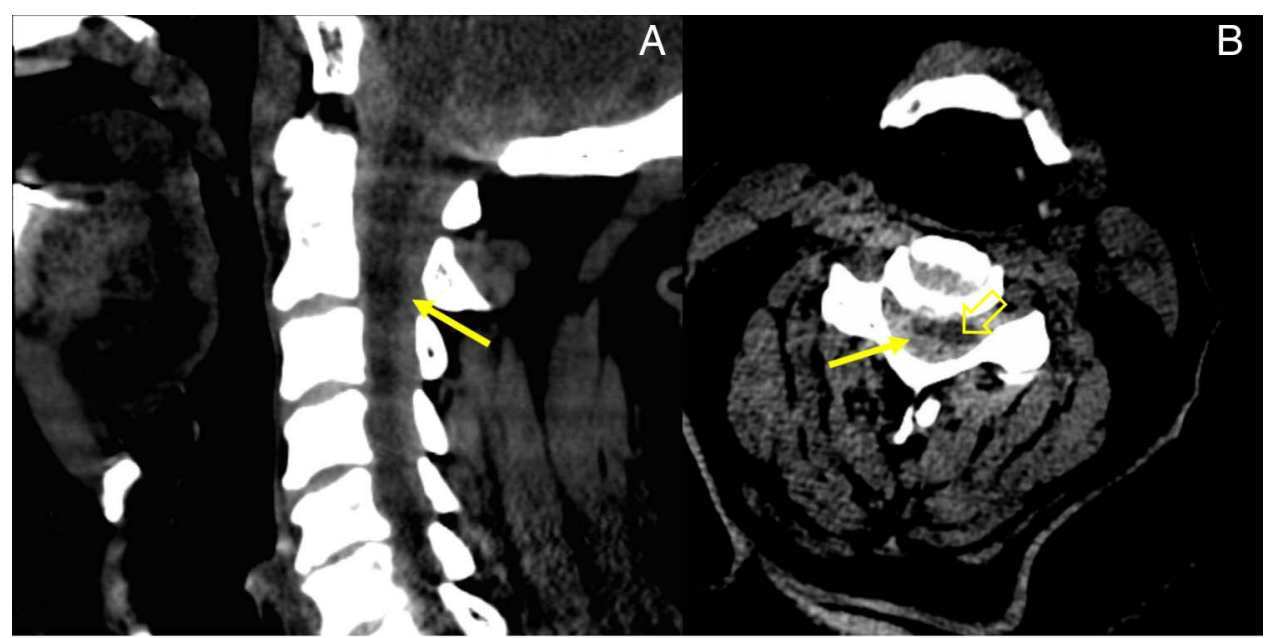




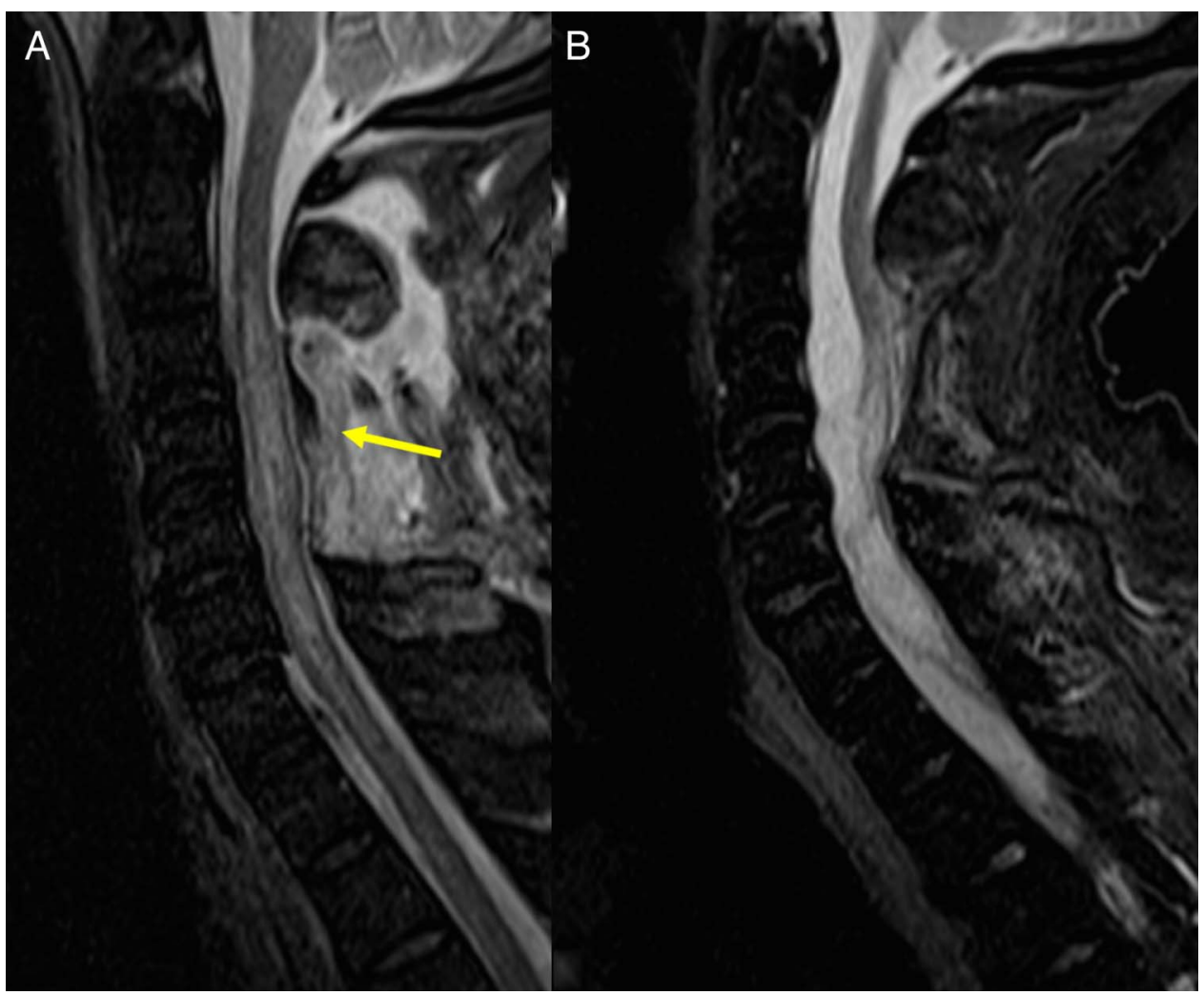

Figure 3 T2-weighted MRI. Sagittal view. (A) Postoperative imaging of the cervical spinal cord. The absence of the spinous processes as a result of the laminectomy can be seen (arrow). The spinal cord appears thickened. No signs of vascular malformations were detected. (B) Control imaging of the cervical spinal cord obtained 6 months after surgery. The spinal cord appears now thinned with extensive residual damage and adhesions to the posterior wall of the spinal channel.

\section{Learning points}

- Spinal subarachnoid haemorrhage (SSH) is uncommon and a spontaneous origin is extremely rare. Most reported cases of spontaneous SSH present with no neurological signs aside from meningismus and even if they do, they usually resolve without sequelae, because the cerebrospinal fluid helps to dilute the blood, making it more difficult to form a clot. Nevertheless, in some case the blood forms a haematoma, which may compress the spinal cord with devastating consequences. ${ }^{1}$ Some individuals may present with barriers for the free circulation of the cerebrospinal fluid that may favour the formation of the hematoma, although this is difficult to prove without an autopsy. ${ }^{2}$

- Prognostic factors are the velocity of the symptoms progression, the preoperative neurological status, the volume of the bleeding and the time to surgery. ${ }^{1}$ It has been suggested that a dorsal location of the bleeding, as in the present case, is more likely to cause severe spinal cord compression, but this has not been proved. ${ }^{2}$

- Although spinal angiography might detect an unknown vascular malformation, most cases of arteriovenous malformation or aneurysm might be detected by the presence of abnormal signal in MRI. ${ }^{3}$
Contributors MR cared for the patient and prepared the manuscript. ER assessed the selection of the radiology images and revised the accuracy of the figure legends. AF cared for the patient and reviewed de draft manuscript. SEB provided an appropriate description of the surgery procedure and reviewed the manuscript.

Competing interests None declared.

Patient consent Obtained.

Provenance and peer review Not commissioned; externally peer reviewed.

\section{REFERENCES}

1 Sunada I, Yoshinori A, Kidosaki Y, et al. Spontaneous spinal subarahnoid hematoma —case report. Surge Neurol 1995;44:133-6.

2 Ruelle A, Zerbi D, Andrioli G. Spinal subarachnoid bleeding of unknow etiology. Case reports. J Neurosurg Sci 2001;45:53-7.

$3 \mathrm{Kim}$ JS, Lee SH. Spontaneous spinal subarachnoid hemorrhage with spontaneous resolution. J Korean Neurosurg Soc 2009;45:253-5. 
Copyright 2016 BMJ Publishing Group. All rights reserved. For permission to reuse any of this content visit http://group.bmj.com/group/rights-licensing/permissions.

BMJ Case Report Fellows may re-use this article for personal use and teaching without any further permission.

Become a Fellow of BMJ Case Reports today and you can:

- Submit as many cases as you like

- Enjoy fast sympathetic peer review and rapid publication of accepted articles

- Access all the published articles

- Re-use any of the published material for personal use and teaching without further permission

For information on Institutional Fellowships contact consortiasales@bmjgroup.com

Visit casereports.bmj.com for more articles like this and to become a Fellow 